polarity, pattern formation and nuclear-cytoplasmic interactions are briefly reviewed and also at appropriate times in the other chapters. This style leads to a book that is very readable and well suited to elementary students as well as to the more experienced botanists who will undoubtedly benefit from it.

Cell contents and cell walls are despatched briefly but efficiently in consecutive chapters. All the major organelles are reviewed in up-to-date fashion. It is good to see the most recent views on, for example, $\mathrm{C}_{4}$ chloroplasts and plasmodesmata, although we might have hoped for a more comprehensive assessment of the structure and role of microtubules than the dozen lines allowed for them. Indeed, the whole area of membrane structure and techniques such as freeze-etching is ignored, as is the work on cell wall formation by, for example, Willison and Brown. This is surprising and disappointing in a book that tries to relate structure to function as membranes are of such paramount importance.

It would have been much more useful if the subject coverage in this book had been more evenly distributed. However, taken as a whole, this is an attractive volume that should encourage botanists to think more about how the structure and function of plants are intimately inter-related. Anything that does this is to be welcomed and Dr Cutter has made a notable step in the right direction.

Applied Plant Anatomy (Longman: London and New York, £4.95), by D. F. Cutler, seeks to illustrate the way that a sound knowledge of plant anatomy can be applied to the solution of many important every day problems. It is good, in a textbook of plant anatomy, to see pictures such as that of a papyrus sandal and to read about "wuod in archaeology": this does help the subject to come alive. This novel approach leads to a book that is different from most others on elementary plant anatomy and one that is both readable and enjoyable for even the newest student of botany.

The introductory chapter contains brief notes on techniques for both light and electron microscopy. This is followed by chapters on the basic morphology of plants; a good, simple, illustrated glossary; the histology of plant organs; meristems; vascular tissues; adaptive features; flower and fruit; and economic aspects of applied plant anatomy. Each chapter is well illustrated by clear line diagrams and micrographs. The distribution of micrographs is a little uneven and, indeed, there might have been more of them altogether. At the end of each chapter there is a small list of suggested further reading and, where appropriate, lists indicating where to look to find particular anatomical characters. This is a most valuable addition and covers plants worldwide. The further reading lists are rather too short and often quite dated. Having commented on the usefulness of electron microscopy to the study of plant anatomy, the author then fails to cite a single further reference in this area. Indeed, the four books suggested at the end of chapter one serve as a rather limited coverage of the subject area.

The introductory chapter on techniques is useful but it is a pity that

\section{Principles of plant nutrition}

Principles of Plant Nutrition. By K. Mengel and E. A. Kirkby. Pp. 593. (International Potash Institute: PO Box 41, CH-3048 Worblaufen-Bern, Switzerland, 1978.)

THIs book is broadly based in accordance with the implications of its title and achieves a commendable integration of soil and plant aspects of nutrition. The partnership of geographically separated authors, who are both practically orientated university teachers, provides a background of wide experience and as shown by the principal bibliography (about 1,400 references) an extensive familiarity with the subject.

Chapters 1 to 6 (totalling 290 pages) describe some general principles. Considerable attention is given to plant-soil relationships; nutrient uptake, translocation and storage; nutrient availability in relation to crop needs; generai effects of nutrient deficiencies; and methods of nutrient application and correction. A number of major physiological activities-photosynthesis, nitrogen fixation, nitrogen assimilation, water relations, active transport, nutrient absorption-are described in sufficient depth to provide the necessary background for understanding the role of various elements, although respiration seems less adequately considered.

Chapters 11 to 18 deal separately with each of the familiar essential elementsexcept chlorine, which is reviewed in three pages in a chapter confined to some possibly beneficial or indirectly essential elements: cobalt, silicon and vanadium. Reviews on separate elements cover soil aspects of their availability, their metabolic roles and deficiency and some toxicity effects on growth. These chapters provide a good general idea of the importance of the elements. These and the other chapters are each concluded with a general reading list to supplement some of the figures concerning the resolution of microscopes seem to have been muddled: both TEM and SEM resolution are out by a factor of 100 ! The index is concise and helpful and, indeed, reflects the whole tone of the book, which is to convey a very considerable amount of information in a palatable and easily understandable style.

A. W. Robards

A. W. Robards is Senior Lecturer and Head of the Electron Microscope Laboratory in the Department of Biology at the University of York, UK.

the numerous specific citations in the text.

Chapter 19 concludes the treatise with examples of several toxic or less familiar elements which are discussed in more general terms and it includes several interesting miscellaneous reports. There are a few minor omissions-for example, regarding the production by certain plants of apparently specific citrate and oxalate metal complexes especially with nickel and chromium; the quite extensive work on tungsten relegated here to a few words on page 149 on tungsten inactivation of nitrate reductase by unspecified means; the original, rigorous and model investigations of Brownell on the absolute need for sodium by Atriplex vesicaria (though his later discovery of its possibly general importance in C4-type photosynthesis plants is nevertheless noted); the differentiation of apparently two types of malate enzyme; the exciting conclusions of Meish et al. regarding the essential role of vanadium in green algae, thought to involve the formation of delta aminolaevulinic acid (though this news may have 'broken' as the book went to press); and finally (though possibly again just too late), the further work of Polacco on the need for nickel in urea metabolism since the first report on urease by Dixon et al. briefly cited on page 514 .

This quite comprehensive and well documented book will be of value to students and lecturers alike in faculties of agricultural science, botany and biological sciences and should also be welcome in the libraries of agricultural institutes, advisory workers and consultants. It is especially commended for its relevance to practical aspects of crop nutrition and for proper appreciation of the general principles on which practice should be hased.

E. J. Hewitt

E.J. Hewitt is Head of the Plant Physiology and Biochemistry Section at Long Ashton Research Station, and Reader in Plant Physiology at the University of Bristol, UK. 